\title{
STP Development for Rejuvenation of Declining Industrial City: Kitakyushu, Japan
}

\author{
Sangryong Cha* and Yasuo Miyakawa \\ Dept. of Economics, University of Nagasaki, ${ }^{1}$ and College of Contemporary Japanese Studies, Kogakkan University, ${ }_{1}$ Japan
}

\begin{abstract}
This paper provides a case study to explore the Kitakyushu case as a good referential example on STP development for rejuvenation of declining industrial city. The major data for the case, basically, has been sourced from some materials published by the municipality of Kitakyushu City, the website of the Kitakyushu Science and Research Park (KSRP) etc. The City of Kitakyushu has promoted the KSRP development to overcome industrial decline and stimulate city renaissance as a new industrial city. The core of the development was to develop a high-level education and research environment by gathering several HEls into one campus. Based on the environment, the Kitakyushu Foundation for the Advancement of Industry and Science and Technology (FAIS) played the critical role as a coupler to make various networks and boost industry-academiaadministration innovation. The KSRP, and then, has been designated as a project area of some cluster projects initiated by the central government. It means that local projects can be synchronized, synergized and synthesized with national projects in the KSRP. In addition, through a series of the environmental approach from the Kitakyushu Eco-town Project to the Low Carbon Society Project, the development of the KSRP is being extended into the region. In the Kitakyushu case, networking is the essence of the KSRP development from the planning stage. First of all, the plan put emphasis on networking of academia for the knowledge creation based on competitive collaboration that is expected as the mainspring of rejuvenating declining industrial area and making a new industrial city that the plan aimed. Then, the roles of two organizations are very important for networking, especially networking of networks: the Campus Management Committee as an interface and the FAIS as a coupler. STP development without some strategic considerations for networking as the way of interaction among its participants cannot be a tool to promote innovation and rejuvenate a declining industrial area. The Kitakyushu case mentioned above explains the matter clearly.
\end{abstract}

Keyword : STP development, declining industrial city, networking of networks

\section{INTRODUCTION}

In the last three decades, science and technology parks (STPs) have emerged in many countries in the world. STPs (alternatively called research parks, technopolises and science town etc.) are spatial things with various buildings and facilities dedicated to scientific and technological research

*Correspondence to : Sangryong Cha

Ph.D., Associate Professor

Faculty of Economics, University of Nagasaki, Japan

E-mail : cha@sun.ac.jp

World Technopolis Review

Copyright $\odot$ World Technopolis Association

CC This is an open-access article distributed under the terms of the Creative Commons Attribution Non-Commercial License(http://creativecommons.org/licenses/by-nc/3.0) which permits unrestricted noncommercial use, distribution, and reproduction in any medium, provided the original work is properly cited on a commercial and industrial footing. However, a more persuasive reason of the popularity of STPs may be the capacity to cover the whole range of institutions and relationships involving in process of creation of science, innovation of technology, improvement of industry, and evolution of market based on networking. And nowadays, STPs, which have been developed to commercialize research results from universities in Europe and America from 1950s, became symbolic places or institutions to promote industrialization of science and technology (S\&T) in the era of knowledge-based economy. It means that STPs have substituted for usual industrial parks as policy tools on regional development especially in urban areas of traditional industrial cities (Castells and Hall 1994).

This paper explores the Kitakyushu case as a good referential example on STP development for rejuvenation of 
declining industrial city and it is expected that we can learn some lessons from it.

\section{CONCEPTUAL SKETCH ON STP DEVELOPMENT}

The STP concept has come to be used frequently, but often with quite different meanings and images because definitions of a STP vary considerably around the world and significant variations occur within an individual nation $s$ approach (Cha 2006).

While STPs vary widely in size, shape and location, the broad concept of STP development is one of a spatial development where the interface of research with commerce and industry is encouraged for the better exploitation of technology (UKSPA 2006). From this point of view, STPs can be also defined as organizational entities that sell or lease spatially contiguous land and/or buildings to businesses or other organizations whose principal activities are basic or applied research or development of new products or processes (Luger and Goldstein 1991). It offers a number of shared resources such as uninterruptible power supply, telecommunications hubs, reception and security, management offices, restaurants, bank offices, convention center, parking, internal transportation, entertainment and sports facilities etc. In this way, STPs can offer considerable advantages to hosted companies by reducing overhead costs with these buildings and facilities ${ }^{1}$.

On the other hands, the UK Science Park Association (UKSPA) definition of a STP is a business support and technology transfer initiative that encourages and supports the start-up and incubation of innovation-led, high-growth, knowledge-based businesses, provides an environment where large and international businesses can develop specific and close interactions with a particular centre of knowledge creation for their mutual benefit, and has formal and operational links with centres of knowledge creation such as universities, higher education institutes (HEIs) and research organization (UKSPA 2006). From this perspective, certain dominant reasons for STP development constantly have recurred as follows (Massey, Quintas and Wield 1992):

$\square$ STPs will promote the formation of new firms.

$\square$ STPs will facilitate links between the host academic institutions and park firms and thus improve the takeup of ideas to new products and processes.
Firms on the STPs will have a high level of technology and be at the leading edge; STPs promise a sunrise future, in many areas to replace a sunset existing local economy.

TPs will create employment opportunities.

These, then, are the assumed potential effects of STP development to revitalize local economies. There are five ways in which STP development can boost local economic development and increase local innovative capacity as follows (Kang and Oh 1998):

$\square$ STP development can encourage and facilitate the formation and growth of new businesses based upon the research knowledge and expertise available within a HEI or other center of research. In addition, STPs can also play an important role in complementing regional business promotion activities both in promoting the establishment of new businesses and furthering the growth of existing businesses.

$\square$ STP can act as a catalyst for changes in a region.

$\square$ STP development has the potential for achieving a synergy of technological innovation through interpersonal communication networks.

$\square$ STPs can act as a mechanism to upgrade the technological sophistication and value added of existing industry by providing a location where technical support can be given to local firms which manufacture and market products.

$\square$ STP development highlights the importance of environmental and infrastructure factors in technology-led economic development.

The extent and nature of linkages between business sector and R\&D sector based on a STP are expected to contribute to the success of STP development and the amount of induced economic growth in the region (Luger and Goldstein 1991). Firstly, the linkage between R\&D sector including universities and a STP is expected to create localization economies that attract new R\&D activity to the region and spin-offs. Secondly, the link between a STP and a region $s$ existing businesses may also provide benefits in both directions. Every STP is developing necessarily as a subset of a local, culturally bounded network of human interaction, where both formal and informal associations between

\footnotetext{
${ }^{1}$ http://en.wikipedia.org/wiki/Science_park
} 
business sector and R\&D sector through knowledge flows and profit circulations foster joint innovation activities (Launonen and Viitanen 2011). In many cases, these networks and associations provide a mechanism to facilitate dynamic movement of knowledge and profit between business sector and R\&D sector, and the sum of all these networks and associations is a vast regional network of networks which composed of many smaller networks of contributors to STP development. From this point of view, STPs can be open platform for co-creation or co-evolution between business sector and R\&D sector, which have physical and institutional infrastructure for it.

Based upon some literature reviews aforementioned, we can define the framework of STP development for the case study in this paper as follows: as an ideal type, the framework consists of business sectors and R\&D sectors centering on a STP as an open platform based on its hardware architecture (infrastructure) and software framework (innovation system) in an identifiable economic place where has a physical and institutional environment for symbiosis in a particular area. All kinds of interrelationship for co-creation or co-evolution in it are formed by networks linked through a value flow consisting of knowledge flows and profit circulations (Fig. 2.1).

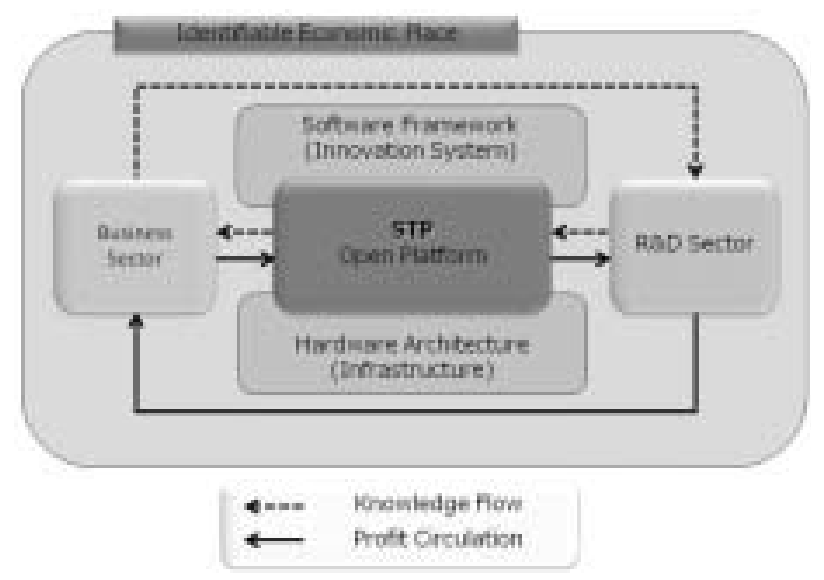

Fig. 2.1 Framework of STP Development

\section{STP DEVELOPMENT AND EVOLUTION IN KITAKYUSHU}

\subsection{Background: Industrial Decline and City Renaissance}

The City of Kitakyushu is a core of the Kitakyushu Industrial Area that is one of the four major industrial areas in Japan ${ }^{2}$. The area of city at present was gained through the merger of five old cities which had functional identity severally: Wakamatsu (port for coal distribution), Moji (trading port), Yahata (ironworks), Tobata (coastal industrial area), and Kokura (military base and arsenal). These five cities had constituted the consecutive and the industrial development mechanism which embedded in the regional structure like demand creation (Kokura) - resource procurement (Wakamatsu) - production (Yahata and Tobata) - marketing (Moji), and it was considered as a unified industrial area. In other words, it can be said that the space structure of Kitakyushu City was a form where the mechanism of industrial development that brought the improvement of productivity of steel industry appeared as a space structure of the city (Fig. 3.1.1).

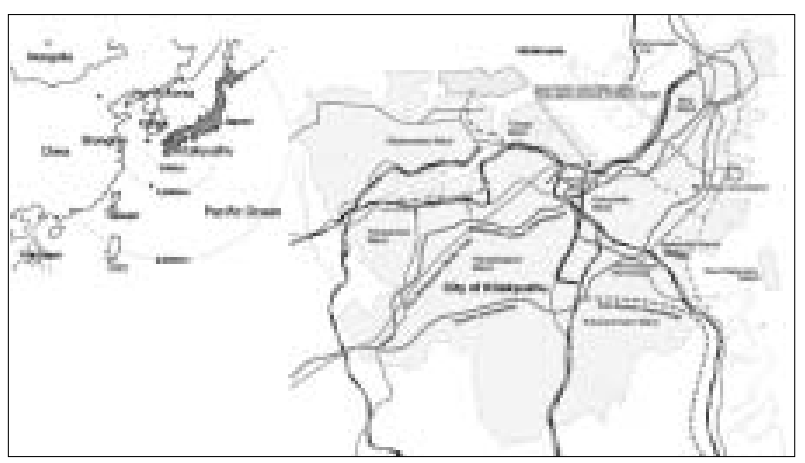

Fig. 3.1.1 Location of Kitakyushu City and Its Spatial Structure

Source: http://www.city.kitakyushu.lg.jp (2007.9.18), edited by Author

However, the industrial development mechanism of this area, as a base of iron manufacture and coal distribution which had supported the industrialization and the military power of Japan, did not operate well from 1955 and the regional economy began to be sluggish. As a result, a lot of companies were moved to new industrial areas such as Keihin Industrial Area or Hanshin Industrial Area from this area, and a lot of residents also left with it. In spite of the merger in 1963, the decline of Kitakyushu did not get better (Table 3.1.1).

In 1988, the Kitakyushu Renaissance Plan to regenerate the locality was drawn up. This plan pursued the keynote theme international technology city as a new industrial city model based on rich natural environment and active exchange supported by high-technology until 2005. And,

\footnotetext{
${ }^{2}$ Keihin Industrial Area , Hanshin Industrial Area, Chukyo Industrial Area, and Kitakyushu Industrial Area
} 
Science and Research City based on STP development was a city image to be aimed at the Plan.

Table 1. Science cities: an international comparison.

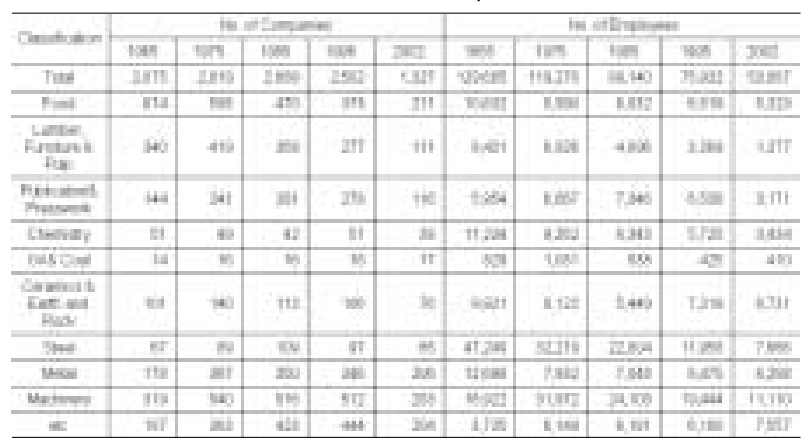

Source: the City of Kitakyushu, 2003

\subsection{Scheme on New University of Kitakyushu and Kitakyushu Science and Research Park (KSRP)}

According to the master plan drawn up in 1989, the purpose of the KSRP development is to build a core of S\&T in Asia for technology advancement and new industry creation making the most use of the geographical advantage, local condition as the biggest cluster of industrial technology in the Western Japan, and experience of technological cooperation in environmental fields with other Asian countries.

It goes without saying that the collaboration between academia and industry is very important in high technology development. Unfortunately, however, it is hard to say that the City of Kitakyushu as a typical industrial city already had enough foundation for the collaboration although there are many good high education institutes (HEIs) such as the Kyushu Institute of Technology in the city. In the master plan, therefore, it was emphasized that the KSRP aims to create new industries and further development of technology by promoting collaboration between academia and industry in there.

The conceptual framework of academia-industry collaboration in the KSRP showed on the Scheme on New University of Kitakyushu. It is to make an active and advanced environment for research and education, gather HEIs which are national, municipal, and private ones with science or engineering faculties into one campus, and encourage competitive collaboration between academia and industry within and outside the campus through various joint researches. It was the first attempt ever made in Japan to develop a high-level education and research environment by gathering several HEIs, which have very different academic traditions one another, into one campus (Fig. 3.2.1).

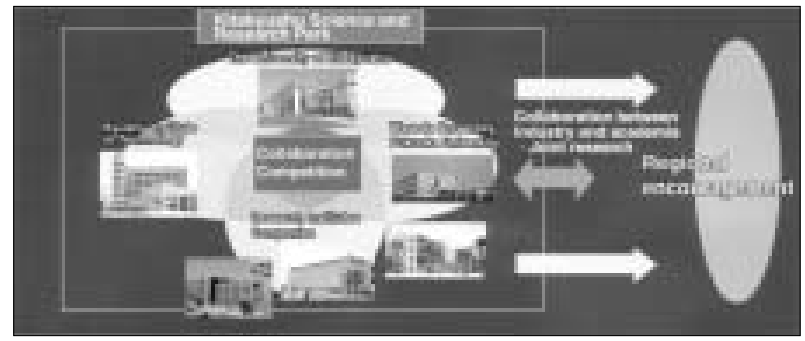

Fig. 3.2.1 Scheme on New University of Kitakyushu Source: the City of Kitakyushu, 2003

To realize the scheme, the KSRP has been developing with the idea of multi-perspective town development taking advantage of surrounding nature and urban environment, which providing a favorable residential environment and the accumulation of education and research institutions related to leading-edge science and technology. The KSRP, which is developed on the site of about 335ha in the northwestern part of Yahatanishi Ward, has a population of 12,000 and households of 4,000 in the plan. The site was developed by the land readjustment project, and the development project was divided into three terms and promoted gradually. The first stage of the project developed 121.4ha in the southern part of the site including the present university zone from 1995 to 2003, and Urban Development Corporation (present Urban Renaissance Agency) took charge of this project. In the second stage of the project, the City of Kitakyushu has a charge of the project to develop 135.5ha in the northern part of the site from 2004 to 2011 . The third stage of the project is to develop the other 67.9ha except 10ha of the river of the site, and it is under examination now (Fig. 3.2.2).

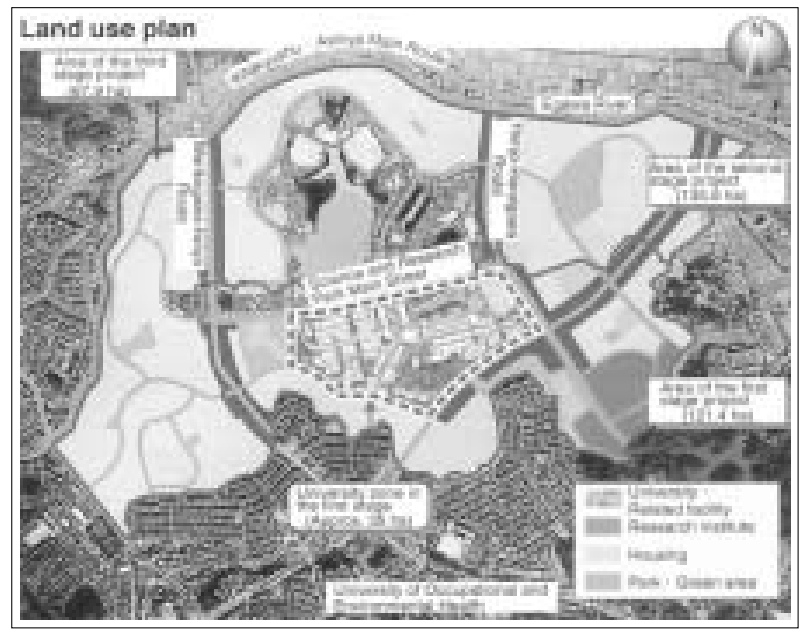

Fig. 3.2.2 Land Use for KSRP Development

Source: FAIS, 2003 
There are four HEIs ${ }^{3}$, sixteen research institutes, and fiftysix companies in the KSRP ${ }^{4}$. HEIs share their education and research ideas with each other, promote advanced education and research in leading-edge technology, encourage academia-industry collaboration and entrepreneurship, and support international student. The Campus Management Committee, which consists of the representatives of each tenant HEI for united management of the campus, plans policy on which it jointly worked and executes sharing facilities such as libraries, computer rooms, and other facilities prosperity. Various challenges for exchange and collaboration among researchers, teachers and students in the KSRP such as joint research, credit transfer system, faculty exchange, and co-hosting congress etc. are tried based on it.

The KSRP aims to link research and education with business and industrial field directly. For example, about thirty percent of 150 faculty members in total of the KSRP have business experience. They have contributed to the progress of research and education activities in the KSRP directly linked with business and industrial fields. In addition, such a directivity of the research and education activities to the real business and industrial fields has been strengthened through various research institutes in the KSRP'. Only, although various actors in industry, academia and government had gathered, the KSRP is specialized for two technology fields: environment and information which are the most useful technology fields in terms of the purpose of the KSRP development because the Kitakyushu Industrial Area is still one of the biggest industrial agglomerations of environment and semiconductor businesses in the Western Japan.

\subsection{Role of FAIS}

The Kitakyushu Foundation for the Advancement of Industry and Science and Technology (FAIS) aims to contribute to the creation of new businesses and the sophistica- tion of industrial technologies through encouraging knowledge flow and profit circulation between R\&D sector and business sector based on the infrastructure and innovation system of the KSRP as an open platform for regional innovation in the City of Kitakyushu. To achieve this aim, the FAIS consists of the executive board, six subordinate organizations: the Campus Administration Center, the SME Support Center, the Industry-Academia Cooperation Center, the Semiconductor Technology Center (the former SoC Design Center), the Car Electronics Center (the former Human Technology Based Cluster Development Center), and the Bureau for Robot Development Support (the former Robotics Research Institute).

In terms of policy making in the initial stage of the KSRP development, the executive board structure is interesting. In 2001 when the FAIS was established together with the opening of the KSRP, the executive board consisted of nineteen members from industrial world, academic community, and administration ${ }^{6}$. The president of the executive board was the former minister of Education ${ }^{7}$ (MEXT) and the former president of the University of Tokyo. It means that the FAIS obtained the political negotiation power in the national level through him and got a chance to synchronize its strategies with national policies such as the Knowledge Cluster Initiative by MEXT in the initial stage. Moreover, the other members who are representatives of industrial world, universities, and civil servants in the locality also contribute to improving the political negotiation power of the FAIS at the local or region level. The FAIS, that is, could improve the practice possibility of projects based on its network of networks which consists of the vertical network among nation, region and locality and the horizontal network among industry, university and administration owing to this political negotiation power of the executive board. In a local city such as the City of Kitakyushu where resources for policy making

\footnotetext{
${ }^{3}$ Faculty of Environmental Engineering, University of Kitakyushu (municipal), the Graduate School of Life Science and Systems Engineering, Kyushu Institute of Technology (national), the Graduate School of Information, Production and Systems, Waseda University (private), and the Graduate School of Engineering, Fukuoka University (private).

${ }^{4}$ As of June, 2011

${ }^{5}$ For instance, the Kyushu Laboratory of Advanced Research Institute for Science and Engineering, Waseda University aims at the academia-industry collaboration while doing a wide approach from basic theory to practical business research as a Kyushu hub of the research institute with the tradition to have contributed to the development of science, technology and industry of Japan in the field of environment, construction, telecommunication, system LSI, and robotics, etc. And, the Cranfield University at Kitakyushu has been trying to research jointly by industry-university cooperation in the field of the aeronautical engineering as a foreign research institute. Moreover, the Fukuoka Research Center for Recycling Systems has tried to match a recycling technology with the social system for the development of resource recycling society.

${ }^{6}$ In 2011, the executive board of the FAIS consists of eighteen members.

7 the Ministry of Education, Culture, Sports, Science and Technology at present.
} 
are relatively limited, it is effective to build the network of networks in multi-dimension and various fields above mentioned for concentrating regional competence.

On the other hand, six subordinate organizations are specialized separately for a specific role or project. To put it concretely, the Campus Administration Center carries out operations of the FAIS, administers the common-use facilities and promotes collaboration and exchange among universities. The SME Support Center supports R\&D at SMEs by providing research funding and $\mathrm{SOHO}$ office, promoting collaboration projects between industry and academia, and providing on-site consultation service. The Industry-Academia Cooperation Center supports improvement of local industries and creation of new industries through coordinating collaboration projects between industry and academia, gaining patents for technological seeds of universities and transferring technologies of companies.

Based on it mentioned above, the FAIS has been played the role as a "coupler" that unites two or more different organizations and functions like one organization to boost collaboration between R\&D sector and business sector in the KSRP and promote the creation of new industry in the region (Cha 2011). While various organizations in the KSRP are synchronized with each other through the FAIS, the KSRP can play the role as an open platform which supports the role of the FAIS as a coupler. In this way, the FAIS has contributed to strengthening the innovation competence of the KSRP. For instance, the number of joint research supported by external funds has persistently increased since 2001 though it slightly came town after the climax of 2005 , and the number of patent application and license agreement in the running total has also increased every year since 2001 (Fig. 3.3.1; 3.3.2).

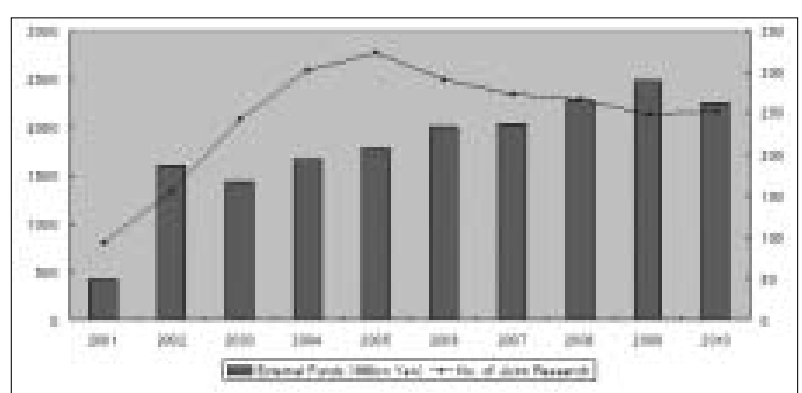

Fig. 3.3.1 Change of External Funds and Number of Joint Research in the KSRP

Source: by Author based on the data from the KSRP's webpage (http://www.ksrp.or.jp)

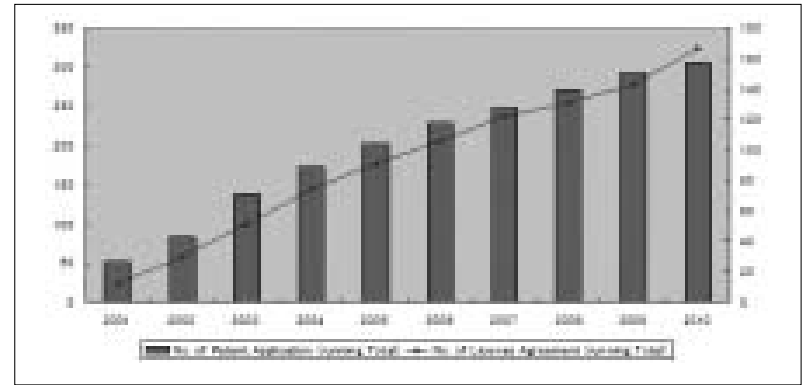

Fig. 3.3.2 Number of Patent Application and License Agreement by FAIS Source: by Author based on the data from the KSRP's webpage (http://www.ksrp.or.jp)

\subsection{Cluster Projects}

The KSRP has been designated as a project area of some cluster projects initiated by the central government. It means that local projects can be synchronized, synergized and synthesized with national projects in the KSRP.

For example, on April 2002, the KSRP was designated as a project area of the Knowledge Cluster Initiative named the Kitakyushu Human Technology Cluster. This project aimed to create new environmental industries and its cluster. To create new environmental industries, a lot of joint researches between academia and industry were conducted by this project based on the knowledge foundation of the KSRP and the technology base accumulated by local industries in the field of environment, life/safety and health.

On the other hand, the FAIS participated in the Industrial Cluster Project named the Kyushu Silicon Cluster which was another national project started from 2001 in semiconductor/FPD'-related fields. The 138 companies, 10 universities, 11 local governments, 13 industry support organizations, and 64 individuals participated in the Kyushu Semiconductor Industries and Technology Innovation Association (SIIQ) which is the promotion organization of this project. The FAIS, of course, is also one of them.

As the FAIS participated in the SIIQ, the members of the Kitakyushu Human Technology Cluster got more detailed information about the participants of the Kyushu Silicon Cluster. It means that they got a chance to synchronize their research activities in the KSRP with the development activities of the Kyushu Silicon Cluster project in Kyushu and syn-

\footnotetext{
${ }^{8}$ A coupler means a device that unites two circuits related with electricity or electron, and that automatically synchronizes one keyboards with the other keyboards, keyboards with pedals or one note with another note related with music. ${ }^{9}$ Flat Panel Display
} 
ergize with each other for achieving their own goal. In this context, they organized the Kyushu Wide Area Cluster Combined Headquarters Committee cooperating with members of the Fukuoka Project of a Cluster for System LSI Design and Development which was the other project of the Knowledge Cluster Initiative in Kyushu, and held a joint conference named Synergy Kyushu 2003.

The vision of the Kyushu Wide Area Cluster that the socalled "Silicon Island, Kyushu" become a hub of system LSI development in Asia was succeeded by the Fukuoka Cluster for Advanced System LSI Technology Development as a new project of the Knowledge Cluster Initiative (the Second Stage) in Fukuoka, Kitakyushu, and Iizuka area from 2009. The part related with SoC technology of the Kitakyushu Human Technology Cluster project was synthesized with this project and keeps on their research under the new framework of national policy titled the Regional Innovation Cluster Program (Global Type) from 2011.

\subsection{Green Innovation: from Eco-town to Low Carbon Society}

"Environment" is one of the keywords to understand the KSRP development because the City of Kitakyushu is a symbolic place to overcome environmental pollution occurred in the process of modern industrialization. Based on the experi-

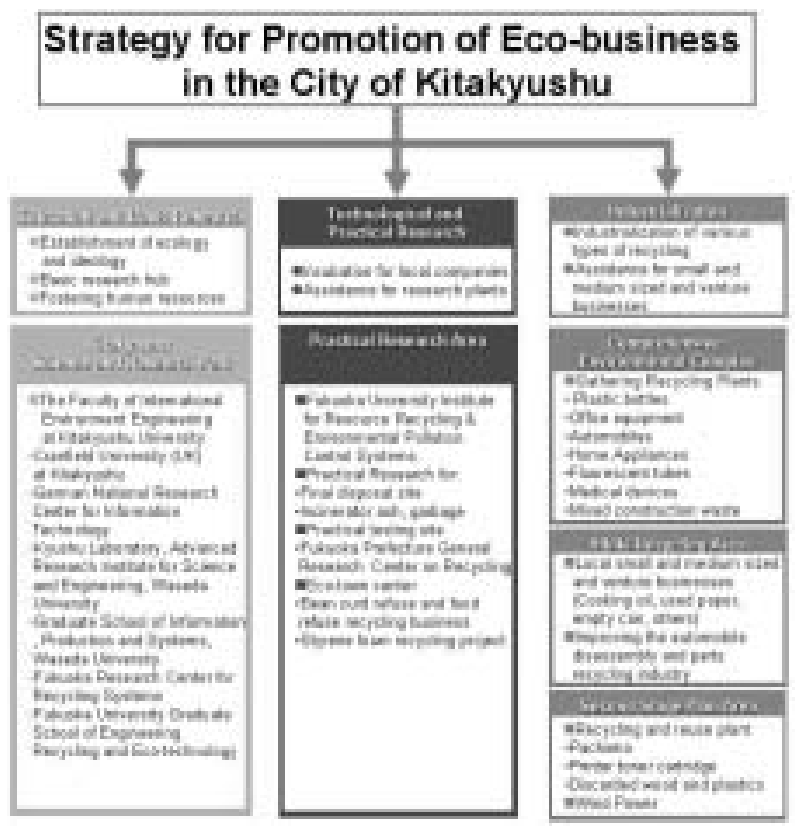

Fig. 3.5.1 The Strategy for Promotion of Eco-business in the City of Kitakyushu Source: by Author ences to overcome industrial pollution, the City of Kitakyushu strategically chose an environmental approach for regional renaissance of the city visioning a "Resource Recycling-based Economic Society." The Kitakyushu Eco-town Project was started based on such strategic conception, and it is a starting point of green innovation based on the KSRP development.

The project aims to develop eco-business totally from education and basic research in the KSRP to technological and practical research in the Practical Research Area, and industrialization in the Comprehensive Environmental Complex and the Hibiki Recycle Area (Fig. 3.5.1).

The results of basic research in the KSRP can be "Seeds" for various empirical researches as sub-projects of the ecotown project in the Practical Research Area where there are sixteen facilities for industry-academia research partnership. Through the empirical researches, some of technological seeds from the KSRP evolved in the Comprehensive Environmental Industrial Complex for industrialization of the environmental technology and zero emission. There are

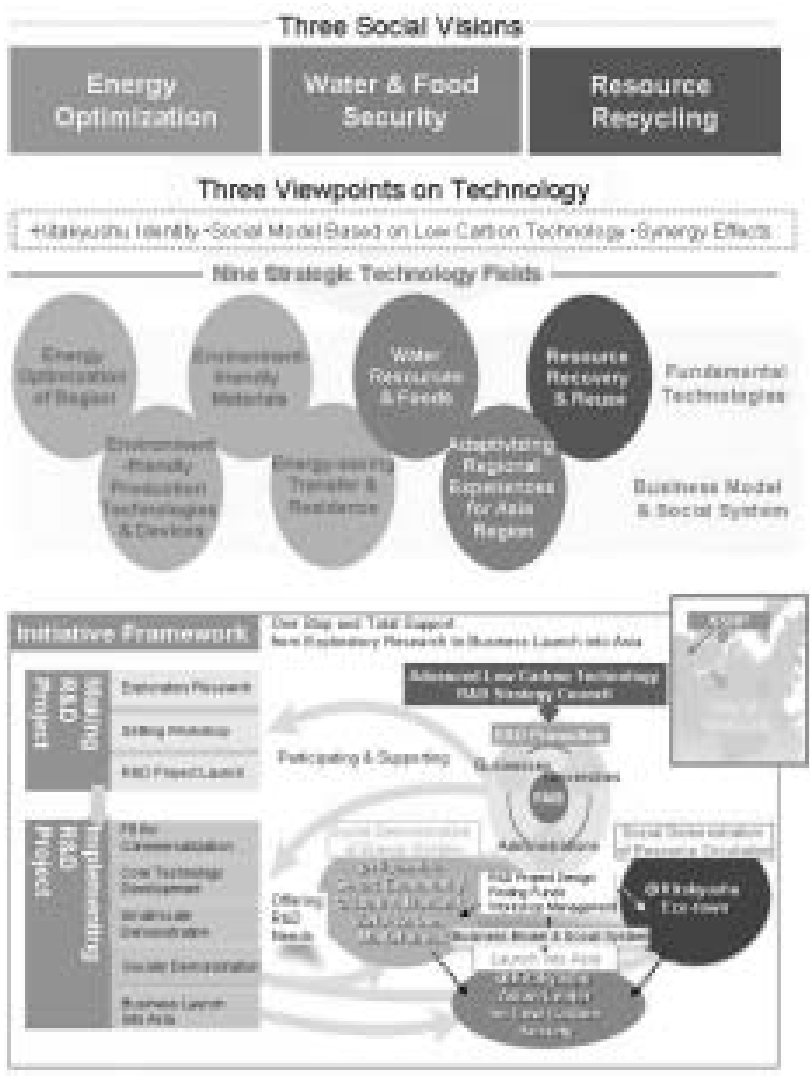

Fig. 3.5.2 Kitakyushu Smart Community Project

Source: by Author based on the data from the KSRP s webpage (http://www.ksrp.or.jp) 
various recycling companies such as PET bottles, an office equipments, cars, home appliances, fluorescent tubes, medical devices, and mixed construction wastes in there, which companies are trying to commercialize recycling technology.

The Kitakyushu Eco-town Project is the first eco-town project approved by the government in Japan (GEC 2005). And also, the Eco-town Center, the Hibiki Recycling Complex, and the Comprehensive Environmental Industrial Complex were the first only targeted areas for the eco-town project. This kind of strategic nature as an environmental model city is also demonstrated in the Advanced Low Carbon Technology Research and Development Strategic Guidelines which released on January 2011. The FAIS got a chance to manage the future direction for low carbon technology research and development in the City of Kitakyushu (Fig. 3.5.2).

The guidelines have been formulated to build a research hub for low carbon technologies and promote local industries featuring the low carbon technologies by providing developmental support. Setting up three social visions (energy optimization, water and food security, and resource recycling), the guidelines will tackle nine strategic technology fields from three viewpoints, including utilization of local potentialities. The City of Kitakyushu will establish ten study groups aiming to create 75 projects for the research and development within five years. By establishing the Project Planning Office (tentative name) based on industry-academia-administration collaboration, these projects will be operated. It goes without saying that the main place for the project operation will be the KSRP and the STP development will be extended through it into the City of Kitakyushu.

The Kitakyushu Smart Community Creation Project from August 2010 is also a green innovation project on the framework of the Guidelines. This project implements various demonstrations to 2014, and the demonstration results are used in the Higashida district, the Yahata-higashi ward, as stepping-stones to expanding the project to all areas of the city. The Higashida district (approximately $120 \mathrm{ha}$ ) is investing 16.3 billion yen over the five-year period, which is founded on a basic plan to (1) adopt renewable energies such as solar power generation on a large scale; (2) establish a consumer-participatory energy system by means of a smart grid; (3) reduce energy consumption in places such as homes and buildings; (4) introduce electric vehicles and fuel-cell cars on a large scale; and (5) engage in highly comfortable and convenient town develop-

\footnotetext{
${ }^{10}$ http://www.gov-online.go.jp/eng/publicity/book/hlj/html/201107/201107_05.html
}

ment through these activities ${ }^{10}$. In the district, moreover, the Kitakyushu Hydrogen Town Project as a part of the Kitakyushu Smart Community Project was newly launched in January 2011. The project marks a world-first attempt to use a pipeline to supply the hydrogen generated in the iron manufacturing process at iron foundries to operate fuel cells.

By the way, the implementation body of the project is the Kitakyushu Smart Community Council which consists of 46 companies and organizations including Nippon Steel Corp., the University of Kitakyushu, local government, and the FAIS. It is interesting that many of the KSRP s members such as the FAIS participate in the council. While the council participates in planning and promoting all of the sub-projects for building the Kitakyushu Smart Community, R\&D activities in the KSRP will be synchronized, synergized, and synthesized with this project toward green innovation by the participants from the KSRP.

\section{CONCLUSION}

It is clear that a STP is a spatial being: there is a scale of space that various buildings or facilities related with R\&D, practical education, and test production occasionally are located. Therefore, it may be necessary to make a good physical environment with charming design luring various players in the development of STP. However, it is not just a physical environment for gathering such buildings or facilities up. Rather it can be said as a specific place that innovative ethos to create new knowledge carrying industrial or economic value is blown up through various interactions under the science initiative. From this point of view, networking on the context of STP development can be said as a work to change individual and separate actions of STP citizenry into interactions among them and make an innovation community that occupies space of STP and changes it into the locus of innovation. For that reason, it is argued that STP development can be a useful leverage point and policy measure to rejuvenate decling industrial areas.

In the Kitakyushu Case aforementioned, networking is the essence of the KSRP development from the planning stage. First of all, the plan put emphasis on networking of academia for the knowledge creation based on competitive collaboration that is expected as the mainspring of rejuvenating declining industrial area and making a new industrial city that the plan aimed. To make and activate networking of academia, 
many kinds of motives are given to HEIs and research institutes in the KSRP: joint research, credit transfer system, faculty exchange, co-hosting congress, and campus management committee that consisted of the representative of HEIs. And then, STP as a common physical environment of its members plays the role of catalyst to precipitate the networking through some common-use facilities. Within these facilities, besides, the Collaboration Center, the Semiconductor Center, the IT Advancement Center have some rental labs and project rooms for private companies, and the Annex of Collaboration Center is a core building for joint research among the tenant companies. Networking in the KSRP is more expanded through these facilities into industries.

Then, the roles of two organizations are very important for networking, especially networking of networks: the Campus Management Committee as an interface and the FAIS as a coupler. As mentioned above, the Campus Management Committee consisted of the member HEIs in the KSRP plans policies on which it jointly worked and decides the contents offered through the facilities though the local government bore the expense for the facilities construction. It means that the Campus Management Committee is the point that the member HEIs meet and interact together and it makes a kind of protocol which is a set of rules governing the interaction among them. And the FAIS, as a coupler, connects two different organizations with each other and makes them just like one system through promoting various projects such as joint research, study group, technology transfer etc with the Campus Management Committee.

If we can say that the essence of innovation is new combination, networking is, on the context of STP development, a kind of social innovation for technological innovation because the various organizations of a STP are interconnected with one another and interacted with some creative new ways to create new technology through new combination of knowledge. That is why industry-academia-government relationships have attracted considerable attention as the key to innovation in increasingly knowledge-based societies. But, the important thing is not the relationship itself but the way of interaction. In other words, an industry-academia-government relationship itself is not new one. The real new one that we have to find out to create innovation is the way of interaction among industry, academia and government. A triple helix concept of industry-academia-government interactions, though a little complicated, is a good example from this point of view (Campbell, Koski and Blumenthal 2004;
Etzkowits 2008; Saad and Jawdie 2010). Therefore, STP development without some strategic considerations for networking as the way of interaction among its participants cannot be a tool to promote innovation and rejuvenate a declining industrial area. The Kitakyushu case mentioned above explains the matter clearly.

\section{REFERENCES}

Campbell, N.A., et al.(2009) B iology: C oncepts and C onnections (6th ed.), Benjamin Cummings.

Cha, S.R.(2011) R egional Innovation System and Policy for $\mathrm{H}$ igh- tech Industrial Area in Japan and K orea, Fukuoka: Hanashoin (in Japanese).

Etzkowits, H.(2008) T he T riple H elix: U niersity-IndustryGovernment Innovation in Action, New York: Routledge.

FAIS(2003) The K itakyushu Science and R esearch Park, Kitakyushu: The Advancement of Industry and Science and Technology (FAIS).

GEC(2005) E co-towns in Japan- Implications and L essons for D eveloping Countries and Cities-, Osaka: Global Environment Centre Foundation (GEC).

Miyakawa, Y.(2006) Regional Renaissance and Sustainable Development of Science City in Japan on High Tech Clusters in Global Context, Proceeding of International W orkshop on $\mathrm{H}$ igh- tech Clusters in G lobal Context, Daejeon: UNESCO-WTA Cooperative Project, 99-144.

METI(2008) Industrial Cluster Project, Tokyo: METI.

METI(2009) I ndustrial Cluster Project, Tokyo: METI.

MEXT(2008) Cluster; K now ledgeC luster I nitiative, Tokyo: MEXT. MEXT(2009) Cluster; K now ledgeC luster I nitiative, Tokyo: MEXT. MEXT(2010) White Paper on Science and T echnology, Tokyo: MEXT.

Moor, J.F.(1993) Predators and Prey: A New Ecology of Competition, $\mathrm{H}$ arvard Business R eview 71(3); 75-86.

Yamazumi, K. and Engeström, Y.(2008) Knotw orking: to

$\mathrm{C}$ reation of $\mathrm{H}$ uman Activities $\mathrm{K}$ notw ored, Tokyo: Shinyosha (in Japanese).

http://en.wikipedia.org/wiki/Ecosystem Accessed at 2011.9.30

http://www.city.kitakyushu.lg.jp Accessed at 2007.9.18

http://www.challenge25.go.jp Accessed at 2011. 9. 30

http://www.gov-online.go.jp Accessed at 2011.7.5

http://www.ksrp.or.jp/e/info/index.html Accessed at 2011.9.30 